IRA-International Journal of Applied Sciences ISSN 2455-4499; Vol.03, Issue 03 (2016)

Institute of Research Advances

http://research-advances.org/index.php/IRAJAS

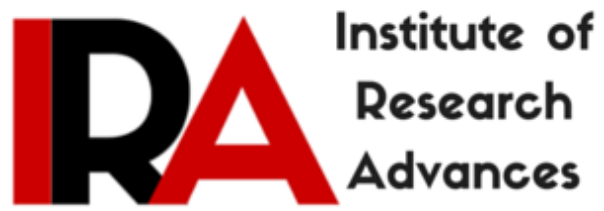

\title{
Reactivity of Benzyl Alcohol and Substituted Benzyl Alcohols with 1-Chlorobenzimidazole in Acid Medium - A Kinetic and Mechanistic Approach
}

\author{
M. Rukmangathan ${ }^{1}$, V. Santhosh Kumar ${ }^{1}$ and B. Ramkumar ${ }^{2}$ \\ ${ }^{1}$ Department of Chemistry, Arasu Engineering College, \\ Kumbakonam, Tamil Nadu, India - 612501 \\ ${ }^{2} \mathrm{PG}$ and Research Department of Chemistry, Government Arts College, \\ Thuvakudimalai, Tiruchirappalli, Tamil Nadu, India - 620022
}

DOI: http://dx.doi.org/10.21013/jas.v3.n3.p20

\section{How to cite this paper:}

Rukmangathan, M., Kumar, V., \& Ramkumar, B. (2016). Reactivity of Benzyl Alcohol and Substituted Benzyl Alcohols with 1-Chlorobenzimidazole in Acid Medium A Kinetic and Mechanistic Approach. IRA-International Journal of Applied Sciences (ISSN 2455-4499), 3(3). doi:http://dx.doi.org/10.21013/jas.v3.n3.p20

(C) Institute of Research Advances

\section{(cc) EY-NC}

This works is licensed under a Creative Commons Attribution-Non Commercial 4.0 International License subject to proper citation to the publication source of the work.

Disclaimer: The scholarly papers as reviewed and published by the Institute of Research Advances (IRA) are the views and opinions of their respective authors and are not the views or opinions of the IRA. The IRA disclaims of any harm or loss caused due to the published content to any party. 


ABSTRACT
The kinetics of oxidation of benzyl alcohol and a few substituted benzyl
alcohols with 1-chlorobenzimidazole (CBI) were studied in aqueous acetic acid
medium. The order of the reactions with respect to each oxidant and substrate was
found to be unity. The added $\mathrm{HClO}_{4}$ increases the rate and the order in $\left[\mathrm{HClO}_{4}\right]$ was
found to be fractional. The reactions were catalyzed by $\mathrm{NaCl}$ and a fractional order
dependence was observed for [NaCl]. The ionic strength had negligible influence on
the rate. Increase in the percentage of acetic acid increases the rate. Addition of
benzimidazole, one of the products does not affect the rate. Effect of temperature on
the reaction rates was studied at different temperatures and the various activation
and thermodynamic parameters were computed. The Hammett plot shows an
excellent correlation with negative $\rho$ value (- O.37) for benzyl alcohols. Product
analysis shows the formation of aldehydes as major products of oxidation of benzyl
alcohols. CBIH ${ }^{+}$has been postulated as the reactive oxidizing species. Suitable
mechanism and the rate law in consistent with the experimental results have been
proposed.

Key words: benzyl alcohol, 1-chlorobenzimidazole, oxidation, kinetics.

\section{INTRODUCTION}

The chemistry of N-halo compounds forms a separate branch which is of great synthetic importance [1-4]. In the recent development, $\mathrm{N}$-halo compounds, the sources of positive halogens, have been extensively employed as oxidizing agents for a variety of organic substrates [5-14]. The nature of the oxidizing species and mechanism of the reactions depends on the nature of halogen atom, groups attached to the nitrogen atom and the reaction conditions.

The kinetics of oxidation of benzyl alcohols with a variety of metal oxidants such as Potassium dichromate [15\&16], Quinolinium dichromate [17], Cetyl trimethyl ammonium dichromate [18], Quinolinium fluoro chromate [19], Quinolinium chloro chromate [20], Benzyl triethylammonium chlorochromate [21], Quinoxalinium bromochromate [22], Benzimidazolium fluorochromate [23], Pyridinium bromochromate [24] and Tetrabutyl ammonium tribromide [25] has been studied earlier. A few N-halo oxidants such as N-bromosuccinimide [26\&27], $\mathrm{N}$-chlorosaccharin [28\&29], N-bromoacetamide [30], Chloramine-T [31], Bromamine- T [32], 1-Chlorobenzotriazole [33], N-Bromophthalimide [34] and 1Bromobenzimidazole [35] have also been used for the oxidation of benzyl alcohols.

The authors have demonstrated the oxidative capacity of 1Chlorobenzimidazole (CBI) for a good number of common reductants [36] and also utilized it for the oxidation of benzaldehydes [37], furfural [38] and cyclanols [39]. An extensive literature survey reveals that no systematic kinetic work hitherto has been done on the oxidation of benzyl alcohols using CBI. In the present investigation, the reaction kinetics and mechanism of oxidation of benzyl alcohol and their substituents with CBI have been studied in aqueous acetic acid medium.

\section{MATERIALS AND METHODS}

\subsection{MATERIALS:}

1-Chlorobenzimidazole (CBI) was prepared and purified by literature method [40]. Acetic acid was purified by standard method and the fraction distilling at $118^{\circ} \mathrm{C}$ was collected. Benzyl alcohol and substituted benzyl alcohols were the purest 
samples available from M/s Fluka Chemical Industries, Switzerland and were used as such. Benzimidazole (BDH, AnalaR) was used as such without purification. Analytically pure compounds such as sodium perchlorate (Germany), sodium chloride, perchloric acid (BDH, AnalaR), acrylonitrile and nickel chloride were used. Perchloric acid was standardized using standard sodium hydroxide solution.

\subsection{KINETIC METHOD:}

All the standard flasks and the reaction bottles were made up of pyrex glass with ground joint stoppers. The volumetric apparatus, pipettes, burettes and standard flasks were standardized by usual methods. An electrically operated thermostat with a jumo contact thermometer (West Germany) working in conjunction with an electronic relay which maintained temperature accurately with fluctuations not more than $0.1^{\circ} \mathrm{C}$ was used. The bath liquid was water and it was covered with a layer of thermocole bits to minimize heat and water loss due to radiation.

\subsubsection{Preparation of standard solutions:}

The standard solution of CBI was prepared by dissolving the required quantity of it in glacial acetic acid and standardized by titrating against sodium thiosulphate solution iodometrically. This standard solution of CBI was found to be invariant in its strength over a period of three months. The solutions of benzyl alcohol and substituted benzyl alcohols were prepared by dissolving the required quantity of these in $80 \%$ acetic acid and $20 \%$ water mixture (v/v).

\subsubsection{Kinetic Measurements:}

All the kinetic reactions were carried out under pseudo-first order conditions, keeping [alcohol] > $>$ CBI] in solvent system $80 \%(\mathrm{v} / \mathrm{v})$ acetic acid-water medium at $308 \mathrm{~K}$ and the courses the reactions were followed potentiometrically [37].

In a typical experiment, the required quantities of the alcohol solutions, perchloric acid, acetic acid-water mixture and sodium chloride solution were pipetted out in a double walled beaker provided with an inlet and outlet for circulating water from the thermostat set at the desired temperature and the solution were kept in the beaker for nearly half an hour to attain the desired temperature. The reaction was started by pipetting out the required quantity of CBI solution which had also been thermostated for nearly half an hour. The total volume of the reaction mixture was always $25 \mathrm{ml}$. A stop-watch was started when half the amount of oxidant was added.

The reaction was followed by setting up a cell

$$
\left[\left.\mathrm{Pt}\left|\mathrm{BI}^{(+)}-\mathrm{CBI}\right|\right|^{(-)} \mathrm{SCE}\right]
$$

made up of the reaction mixture into which the platinum electrode and saturated calomel electrode(SCE) were dipped. The emf of the cell was measured periodically using Equip-Tronics Digital potentiometer while the reaction mixture was continuously stirred using a magnetic stirrer. The pseudo-first order rate constant, $\mathrm{k}_{1}$, was computed from the linear $(r>0.999)$ plots of $\log \left(\mathrm{E}_{\mathrm{t}}-\mathrm{E}_{\infty}\right)$ Vs time.

Where, $E_{t}$ - potential at time ' $t$ '

and $\mathrm{E}_{\infty}$ - potential at infinity.

When the kinetic run was also done by iodometry, the same results were obtained within $\pm 2 \%$. Preliminary experiments showed that the rate of oxidation is not sensitive to change in ionic strength and hence no attempt was made to keep it constant. 


\subsubsection{Product analysis and stoichiometry:}

Different ratio of Benzyl alcohol and CBI were mixed together with $\mathrm{HClO}_{4}$ $(1 \mathrm{M})$ in $80 \%$ acetic acid (total volume $100 \mathrm{ml}$ ). The reaction mixture was kept aside for 48 hours to ensure the completion of the reaction. The solution was extracted with chloroform and the organic layer was washed with water, dried over anhydrous sodium sulphate. Benzaldeyde was formed as the main product which was identified by the formation of 2,4-dinitrophenylhydrazone derivative (m.p $234-236^{\circ} \mathrm{C}$, lit:237 ${ }^{\circ} \mathrm{C}$ ) . The estimation of unreacted oxidant indicated that one mole of the oxidant was consumed by one mole of the alcohol. Further the product benzaldehyde has also been confirmed by its IR and NMR Spectral data.

$$
\mathrm{R}-\mathrm{C}_{6} \mathrm{H}_{4}-\mathrm{CH}_{2} \mathrm{OH}+\mathrm{CBI} \longrightarrow \quad \mathrm{R}_{-} \mathrm{C}_{6} \mathrm{H}_{4}-\mathrm{CHO}+\mathrm{BI}+\mathrm{HCl}-----(\mathrm{i})
$$

\section{RESULTS AND DISCUSSION}

Oxidation of benzyl alcohol and a few substituted benzyl alcohols by 1chlorobenzimidazole has been carried out in $80 \%$ (v/v) acetic acid - water medium in the presence of perchloric acid and sodium chloride at $308 \mathrm{~K}$. In all the cases the corresponding aldehydes are the major products. The rates of the reactions were measured by following the disappearance of $[\mathrm{CBI}]$ potentiometrically. The reactions were followed under pseudo first order conditions where the concentrations of the substrates were in large excess compared to that of [CBI].

The oxidation kinetics of benzyl alcohols by CBI has the following salient features.

(i). The reactions have first order dependence on $[\mathrm{CBI}]$ as revealed by the constancy of the rate constant values obtained from integrated first order equation, linearity of the $\log \left(\mathrm{E}_{\mathrm{t}}-\mathrm{E}_{\infty}\right)$ Vs time plot and invariance of $\mathrm{k}_{\mathrm{obs}}$ values with varying initial [CBI]. (Table.1 \& Fig.1)

(ii). The order of the reaction with respect to [substrate] is unity, $\mathrm{k}_{\mathrm{obs}}$ is directly proportional to [benzyl alcohol] as evident from the constant values of $k_{2}$. Plot of log $\mathrm{k}_{\mathrm{obs}} \mathrm{Vs} \log$ [benzyl alcohol] is also linear with a slope of unity (Table 1).

(iii). Added perchloric acid increases the rate of the reaction. (Table.1). A plot of log $\mathrm{k}_{\mathrm{obs}} \mathrm{Vs} \log \left[\mathrm{H}^{+}\right]$is linear with a slope of $0.58(\mathrm{r}=0.997)$. This shows that the reaction is fractional order dependence with respect to $\left[\mathrm{H}^{+}\right]$indicating the participation of water molecule in the rate determining step [28]. This is further confirmed by Bunnett - Olsen's linear free energy relationship [41] by the plot of $\left(5+\log \mathrm{k}_{\mathrm{obs}}+\mathrm{H}_{\mathrm{o}}\right) \mathrm{Vs}(3+$ $\log \mathrm{C}_{\mathrm{H}}{ }^{+}+\mathrm{H}_{\mathrm{o}}$ ). The slope value $(\phi)$ of the above plot was found to be 1.30 (Fig.2).

(iv). The rate of oxidation increases with decreasing dielectric constant of the medium (Table. 1). A plot of $\log \mathrm{k}_{2}$ Vs 1/D is linear with a positive slope. This is indicative of the fact that the reaction is of an ion-dipole type [42].

(v). Increase in concentration of chloride ions increases the rate of the reaction (Table 1). A plot of $\log \mathrm{k}_{\mathrm{obs}} \mathrm{Vs} \log \left[\mathrm{Cl}^{-}\right]$is linear with a slope of $0.78(\mathrm{r}=0.995)$ shows that this reaction is fractional order dependence with respect to $\left[\mathrm{Cl}^{-}\right]$.

(vi). Initial addition of one of the products, viz. benzimidazole, to the reaction mixture does not affect the rate.

(vii).The reaction rate is not altered significantly with the addition of nickel chloride, a typical chlorine scavenger. 
(viii). Polymerization is not observed when acrylonitrite is added to the reaction mixture.

(ix). Oxidation of substituted benzyl alcohols by CBI has been investigated under comparable conditions. All the substrates follow the same kinetic behaviour as for the parent substrate. Electron donating groups increased the rate while electron withdrawing groups decreased the rate of oxidation (Table.2).

The order of reactivity of substituted benzyl alcohols with CBI is

$$
\begin{gathered}
\mathrm{p}-\mathrm{OCH}_{3}>\mathrm{p}-\mathrm{CH}_{3}>\mathrm{m}-\mathrm{OCH}_{3}>\mathrm{H}>\mathrm{p}-\mathrm{Br}>\mathrm{p}-\mathrm{Cl}>\mathrm{m}-\mathrm{CH}_{3}>\mathrm{m}-\mathrm{NO}_{2}>\mathrm{m}-\mathrm{Cl}>\mathrm{m}- \\
\mathrm{Br}>\mathrm{p}-\mathrm{NO}_{2}
\end{gathered}
$$

(x). Activation and thermodynamic parameters have been calculated for benzyl alcohol and substituted benzyl alcohols (Table. 3). The reaction rates are governed by the changes in both the enthalpy and entropy of activation. This is further supported by the lower values of Ea. The negative values of $\Delta \mathrm{S}^{\#}$ imply the formation of an ionic transition state with an extensive charge separation with a high degree of solvation. Further, the constancy of $\Delta \mathrm{G}^{\#}$ values also confirms the unified mechanism for the oxidation reactions of all the substituted compounds of benzyl alcohol.

(xi). Exner plot is found to be linear with the slope value of $1.08 \quad(\mathrm{r}=0.985)$. The linearity of Exner plot is suggestive of unified mechanism for the CBI oxidation of benzyl alcohol and substituted benzyl alcohols (Fig.3). From the slope of the Exner plot the isokinetic temperature $(\beta)$ is as $201.71 \mathrm{~K}$. Since it is below the experimental temperature range (298-328K), the observed effect of substituents' is real. The value of the slope ' $b$ ' of the Exner plot indicates nature of the reaction and selectivity (Table. 4). Since the slope ' $b$ ' is greater than one and 201.71 is less than $T_{1}(298 \mathrm{~K})$ the experimental data fit the type $(3 \mathrm{~b})$ of Table. 4. These results indicate an increasing selectivity with an increase in temperature and the reaction series is characterized by compensation effect between $\Delta \mathrm{H}^{\#}$ and $\Delta \mathrm{S}^{\#}$.

\section{MECHANISM AND RATE LAW}

4.1. Scheme 1:

CBI like other N-halo compounds may exist in various forms in acid medium as free $\mathrm{CBI}, \mathrm{CBIH}^{+}, \mathrm{H}_{2} \mathrm{O}^{+} \mathrm{Cl}, \mathrm{HOCl}$ and $\mathrm{Cl}_{2}$ etc. Molecular chlorine may not be the oxidizing species since the rate is not influenced by the initially added nickel chloride which is a well known chlorine scavenger. The $\mathrm{H}^{+}$ion dependence on the rate of oxidation of benzyl alcohols cannot be rationalized if free CBI is considered to be active species. The observation that the reaction rate is not influenced by the added benzimidazole eliminates the possibility of $\mathrm{HOCl}$ or $\mathrm{H}_{2} \mathrm{O}^{+} \mathrm{Cl}$ being the reactive species [43\&44]. Hence the most probable oxidizing species is the protonated oxidant, $\mathrm{CBIH}^{+}$ which is revealed by $\mathrm{H}^{+}$ion dependence on the reaction rate. The protonation of $\mathrm{N}$-halo compounds as a pre-equilibrium step has already been proposed in the oxidation of benzyl alcohols by CBT [33] and BBI [35], aliphatic primary alcohols by NCN [45] and BBI [46], cyclanols by CBI [39] and BBI [47] and $\alpha$-hydroxy acids by CBT [48].

The increase in reaction rate with the decrease in dielectric constant of the medium suggests that the interaction to be of positive ion - dipole type. The negligible electrolytic effect observed for the reaction substantiates the reaction between an ionic species and a neutral molecule in step 2. Further the participation of water molecule in the rate determining step is confirmed by Bunnet - Olsen plot giving a slope value $\phi=$ 1.30 which is in good agreement with the slope value $\phi=1.40$ for the oxidation of 
benzyl alcohols by CBT [33]. This clearly indicates that a proton transfer by water molecule occurs in the rate determining step leading to the formation of benzyl hypochlorite intermediate [49]. Hypohalites are known to decompose to carbonyl products [50\&51]. Therefore the following scheme has been proposed for the oxidation of benzyl alcohol by CBI.

$$
\begin{array}{cll}
\mathrm{CBI}+\mathrm{H}_{3} \mathrm{O}^{+} & \stackrel{\mathrm{K}_{1}}{\rightleftharpoons} & \mathrm{CBIH}^{+}+\mathrm{H}_{2} \mathrm{O} \\
\mathrm{CBIH}^{+}+\mathrm{R}-\mathrm{C}_{6} \mathrm{H}_{4}-\mathrm{CH}_{2}-\mathrm{OH}+\mathrm{H}_{2} \mathrm{O} & \stackrel{\mathrm{k}_{2} \text { slow }}{\mathrm{k}_{-2}} & \mathrm{R}-\mathrm{C}_{6} \mathrm{H}_{4}-\mathrm{CH}_{2} \mathrm{O}-\mathrm{Cl}+\mathrm{BI}+\mathrm{H}_{3} \mathrm{O}^{+} \\
\mathrm{R}_{-} \mathrm{C}_{6} \mathrm{H}_{4}-\mathrm{CH}_{2} \mathrm{O}-\mathrm{Cl} & \stackrel{\mathrm{k}_{3} \text { fast }}{\longrightarrow} & \mathrm{R}-\mathrm{C}_{6} \mathrm{H}_{4}-\mathrm{CHO}+\mathrm{H}^{+}+\mathrm{Cl}^{-}
\end{array}
$$

(Scheme 1)

Applying equilibrium conditions for the formation of the oxidant species $\mathrm{CBIH}^{+}$, one can write the equilibrium constant specifically for the formation of $\mathrm{CBIH}^{+}$as

$$
\mathrm{K}_{1}=\frac{\left[\mathrm{CBIH}^{+}\right]}{[\mathrm{CBI}]_{\mathrm{e}}\left[\mathrm{H}_{3} \mathrm{O}^{+}\right]}
$$

$$
\text { Assuming }[\mathrm{CBI}]_{\mathrm{e}}=[\mathrm{CBI}]_{\mathrm{T}}-\left[\mathrm{CBIH}^{+}\right]
$$

where

$$
\begin{array}{ll}
{[\mathrm{CBI}]_{\mathrm{e}}=} & \text { equilibrium concentration of CBI } \\
{[\mathrm{CBI}]_{\mathrm{T}}=} & \text { total concentration of } \mathrm{CBI}
\end{array}
$$

Therefore $\mathrm{K}_{1}=$

$$
\left\{\overline{\left.[\mathrm{CBI}]_{\mathrm{T}}-\left[\mathrm{CBIH}^{+}\right]\right\}\left[\mathrm{H}_{3} \mathrm{O}^{+}\right]}\right.
$$

where from

$$
\left[\mathrm{CBIH}^{+}\right]=\frac{\mathrm{K}_{1}[\mathrm{CBI}]_{\mathrm{T}}\left[\mathrm{H}_{3} \mathrm{O}^{+}\right]}{1+\mathrm{K}_{1}\left[\mathrm{H}_{3} \mathrm{O}^{+}\right]}
$$

and Rate $=\mathrm{k}_{\mathrm{obs}}[\mathrm{CBI}]_{\mathrm{T}}$

$$
=\mathrm{k}_{2}\left[\mathrm{CBIH}^{+}\right][\text {benzyl alcohol }]
$$

$$
\text { Rate }=\frac{\mathrm{k}_{2} \mathrm{~K}_{1}[\mathrm{CBI}]_{\mathrm{T}}\left[\mathrm{H}_{3} \mathrm{O}^{+}\right][\text {benzyl alcohol }]}{1+\mathrm{K}_{1}\left[\mathrm{H}_{3} \mathrm{O}^{+}\right]}
$$




\subsection{Scheme 2 (Mechanism in presence of $\mathrm{Cl}^{-}$ions):}

The oxidant species in the presence of added chloride ions can be expected to be different from those oxidizing species already mentioned on account of the pronounced acceleration in the reaction rates observed in the presence of $\mathrm{Cl}^{-}$ions. It has been well documented that chloride ions interact with $\mathrm{N}$-chloro compounds and release molecular chlorine [45\&52] or species derived therefrom [48\&53]. Since the experimental observations clearly indicate the absence of any $\mathrm{Cl}_{2}$ formation, it is inferred that the more likely oxidant in the presence of $\mathrm{Cl}^{-}$ions would be coordinated species of the type (I) [48\&53].

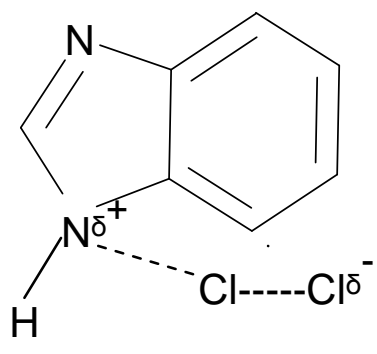

(Type - I)

The influence of added $\mathrm{Cl}^{-}$ions on the rate and mechanism can also be accounted for by a small modification of the scheme 1 . It is assumed in scheme 1 that the reactive species is essentially $\mathrm{CBIH}^{+}$and that $\mathrm{CBI}$ is relatively unimportant. However [CBI] may not be quite negligible at low acid concentrations employed in the experiments and so the reverse hydrolysis of $\mathrm{CBIH}^{+}$has to be taken into account. Also in presence of added $\mathrm{Cl}^{-}$ions a coordinated complex of the type (I) would be envisaged. The true formation constant $\mathrm{K}$ for such a complex can be calculated as follows.

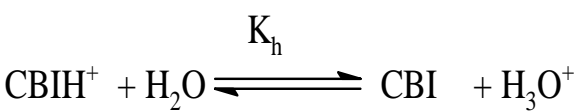

$$
\begin{aligned}
& \mathrm{CBIH}^{+}+\mathrm{Cl}^{-} \stackrel{\overline{\mathrm{K}}}{\rightleftharpoons}(\text { complex }) \\
& \text { complex }+ \text { BA } \underset{\text { fast }}{\stackrel{\mathrm{k}_{2}}{\longrightarrow}} \text { products }
\end{aligned}
$$

where BA = benzyl alcohol

\section{(Scheme 2)}

$$
\mathrm{K}=[\text { complex }]
$$

\section{$\left[\mathrm{CBIH}^{+}\right]\left[\mathrm{Cl}^{-}\right]$}

Assuming $\quad[\mathrm{CBI}]_{\mathrm{T}}=\quad[\mathrm{CBI}]_{\mathrm{e}}+\left[\mathrm{CBIH}^{+}\right]+[$complex $]$

$$
\left[\mathrm{Cl}^{-}\right]_{\text {Total }} \quad>>[\mathrm{CBI}]_{\text {Total }}
$$




$$
\begin{gathered}
{\left[\mathrm{Cl}^{-}\right]_{\text {Total }}-[\text { complex }] \approx\left[\mathrm{Cl}^{-}\right]_{\text {Total }} \approx\left[\mathrm{Cl}^{-}\right]} \\
\text {and } \\
\mathrm{K}_{\mathrm{h}}=\frac{[\mathrm{CBI}]_{\mathrm{e}}\left[\mathrm{H}^{+}\right]}{\left[\mathrm{CBIH}^{+}\right]} \\
{[\text {complex }]=\frac{\mathrm{K}[\mathrm{CBI}]_{\mathrm{T}}\left[\mathrm{H}^{+}\right]\left[\mathrm{Cl}^{-}\right]}{\mathrm{K}_{\mathrm{h}}+\left[\mathrm{H}^{+}\right]+\mathrm{K}\left[\overline{\left.\mathrm{H}^{+}\right]}\left[\mathrm{Cl}^{-}\right]\right.}} \\
\text {Rate }=\mathrm{k}_{\mathrm{obs}}[\mathrm{CBI}]_{\mathrm{T}} \\
=\mathrm{k}_{2}[\text { complex }][\mathrm{BA}]
\end{gathered}
$$

Reshuffling

$\frac{[\mathrm{BA}]}{\mathrm{k}_{\mathrm{obs}}}=\frac{1}{\mathrm{k}_{2}}+\frac{1}{\mathrm{k}_{2} \overline{\mathrm{K}\left[\mathrm{Cl}^{-}\right]}}+\frac{\mathrm{K}_{\mathrm{h}}}{\mathrm{k}_{2} \mathrm{~K}[\overline{\mathrm{Cl}}]\left[\mathrm{H}^{+}\right]}$

Equation (16) predicts a linearity between $[\mathrm{BA}] / \mathrm{k}_{\mathrm{obs}}$ and $1 /\left[\mathrm{Cl}^{-}\right]$at constant $\left[\mathrm{H}^{+}\right]$and also between $[\mathrm{BA}] / \mathrm{k}_{\mathrm{obs}}$ and $1 /\left[\mathrm{H}^{+}\right]$at constant $\left[\mathrm{Cl}^{-}\right]$. Plots of $1 / \mathrm{k}_{\mathrm{obs}} \mathrm{Vs} 1 /\left[\mathrm{H}^{+}\right]$ and $1 / \mathrm{k}_{\text {obs }} \mathrm{Vs} 1 /\left[\mathrm{Cl}^{-}\right]$are linear (Fig. 4 and 5) in the case of benzyl alcohol. From the slopes and intercepts of these plots, the hydrolytic constant $\left(\mathrm{K}_{\mathrm{h}}\right)$ and the true formation constant $(\mathrm{K})$ of the oxidizing species are calculated to be 1.63 and 711 respectively. The corresponding values for $\mathrm{NCSH}^{+}$equilibrium and for $\left[\mathrm{NCSH}^{+}-\mathrm{Cl}^{-}\right]$complex and $\mathrm{CBTH}^{+}$equilibrium and for $\left[\mathrm{CBTH}^{+}---\mathrm{Cl}^{-}\right]$complex are also given in table 5 .

It was estimated from the Hammett plot (Fig.6) that the $\rho$ value of the reaction -0.37 $(\mathrm{r}=0.986)$. The negative $\rho$ value indicates the development of electron deficiency centre suggesting a considerable carbonyl character of the transition state. It is evident from the experimental data that the electron donating groups accelerate the rate while electron withdrawing groups retard the rate. The negative $\rho$ value is similar to the $\rho$ value obtained for the oxidation of aromatic alcohols by NBA [30] and BBI [35]. This again confirms the electron deficiency in the transition state of the reaction and supports the above mechanism.

\section{CONCLUSION}

The kinetics of oxidation of benzyl alcohol and a few substituted benzyl alcohols with 1-chlorobenzimidazole in aqueous acetic acid medium clearly shows that the order of the reaction with respect to [CBI] and [alcohol] are unity and order with respect to $\left[\mathrm{H}^{+}\right]$and $\left[\mathrm{Cl}^{-}\right]$are fractional. The decrease in dielectric constant of the solvent medium increases the rate of reaction significantly. The rate of reaction 
increases with temperature and the various activation and thermodynamic parameters have been evaluated. The mechanism proposed for oxidation kinetics is in accordance with observed kinetic facts.

\section{REFERENCES}

1. Patrocino, F.A.; J Organo Met Chem, 2000,603, 220.

2. Dhurn, P.S.; Mohe, N.U.; Salunkhe, M.M.; Syn Commun, 2001, 31, 3653-3657.

3. Caribano, V.; Rodriguez, J.F.; Santose, M.; Sanz - Tejedor, M.A.; Carreno, M.C.; Gonzalez.; Garcia - Ruano, J.L.; Synthesis., 2001, 14, 2175.

4. Bandgar, B.P.; Upalla L.S.; Sadavarte, V.S.; Synth Lett., 2001, 11, 1715.

5. Mathur, N.K.; Narang, C.K.; Academic press, New York, 1975

6. Thenraja, D.; Subramaniam, P.; Srinivasan, C.; J Chem Soc, 2002, 2, 2125.

7. Mohan, K.; Jagadeesh, M.B.; Indian J Chem, 2008, 47A, 226.

8. Mohamed Farook, N.A.; J Solution Chem, 2007, 36, 345-356.

9. Anil Kumar, J.; Sondu, S.; Indian J Chem., 2007, 46A, 1792-1795.

10. Milind Ubale.; Bull Catal Soc India, 2007, 42, 6.

11. Nanda, N.; Sheshadri, B.S.; Mayanna, S.M.; Reat Kinet Catal Lett, 1999, 67, 35-41.

12. Priya, V.; Balasubramaniyan, M.; Mathiyalagan, N.; J Chem Pharm Res, 2011, $3(1), 522-528$.

13. Gour, S.R.; Dhobalb, B.S.; Sayyed Hussainc .; Mazahar Farooquid, J Chem Pharm Res, 2011, 3(5), 750-761.

14. Singh, R.A.; Kamini Singh Singh, S.K.; J Chem Pharm Res, 2001, 2(3), 684690.

15. Bijudas, K.; Radhakrishnan Nair, T.D.; Indian J Chem, 2004, 43 (A), 1216-1218.

16. Ozgan, B.; Pek, A.; React Kinet Catal, 1992, 33, 74.

17. Doyamoy, D.; Mahanti, M.K.; J Org Chem, 1990, 55, 5848.

18. Sabita Patel.; Mishra, B.K.; Int J Chem Kinet, 2006, 38, 651-656.

19. Arumugam, P.; Velayutham, M.; Oxid Commun, 1997, $20,93$.

20. Ozgun, H.B.; De. Irmenba, N.; J Chem Res (S), 1997, 32.

21. Kaur, R.; Soni, N.; Sharma, V.; Indian J Chem, 2006, 45A, 2441-2445.

22. Degirmenbasi, N.; Ozgun, B.; G U J Sci, 2006, 19(1), 9-13.

23. Dharmaraja, J.; Krishnasamy, K.; Shanmugam, M.; E J Chem, 2008, 5(4), 754760.

24. Narayanan, N.; Balsubramanian, R.; J Chem Res (S), 1991, 12, 336.

25. Gosain, J.; Sharma, P.K.; J Indian Chem Soc, 2002, 79, 815-818.

26. Srinivasan, N.S.; Venkatasubramanian, N.; Curr Sci, 1969, 38, 138.

27. Srinivasan, N.S.; Venkatasubramanian, N.; Indian J Chem, 1972, 10, 1014.

28. Vijayamohan, K.; Ragunatha Rao, P.; Sundaram, E.V.; Proc Nat Acad Sci India, 1988, 58 (A), $37-42$.

29. Gupta, H.D.; Singh, S.K.; Santosh Kumar Singh; J Chem Bio Phy Sci Sec A. 2012, 2 (4), $2311-2319$.

30. Agarwal, A.; Mathur, S.; Banerji, K.K.; J Chem Res, 1987, 176.

31. Ramchandra, H.; Mahadevappa, D.S.; Rangappa, K.S.; Made Gowda, N.M.; Int J Chem Kinet, 1999, 29 (10), 773-780.

32. Rajkishore, S.; Anandan, N.; Mauryaorient, R.C.; J Chem Soc, 1986, 2, 124.

33. Rangadurai, A.; Thiagarajan, V.; Venkatasubramanian, N.; Indian J Chem, 1982, 21 (B), 42-45.

34. Jagdish Bharad.; Balaji Madje.; Milind Ubale.; Int J Emer Tech Comp Appl Sciences, 2013, 13(161), 334-337.

35. Ramkumar, B.; Santhoshkumar, V.; Rukmangathan, M.; Int J Res Phy Che, 2013, 3(4), 14-17. 
36. Rukmangathan, M.; Santhoshkumar, V.; Ramkumar, B.; J Indian Chem Soc, 2010, 87, 1011-1012.

37. Ramkumar, B.; Afinidad, 2003, 60, 505, 257-261.

38. Rukmangathan, M.; Santhoshkumar, V.; Ramkumar, B.; Acta Ciencia Indica., 2011, XXXVII C, (1), 1- 3.

39. Rukmangathan, M.; Santhoshkumar, V.; Ramkumar, B.; J Chem Pharm Res, 2012, 4 (3), 1740-1744.

40. Ramkumar, B.; Asian J Chem, 2001, 13, 777-779.

41. Bunnet, J.F.; Olsen, F.B.; Canadian J Chem, 1966, 44, 1917.

42. Amis, E.S.; Solvent and solvents effects in organic chemistry, Academic press, New York, 1967, 42.

43. Alhaji, N.M.I.; Uduman Mohideen, A.M.; Sofia Lawrence Mary, S.; E- J Chem, 2011, 8 (1), 159 - 166.

44. Mohamed Farook, N.A.; J. Iranian Chem Soc, 2006, 3 (4), 378 - 386.

45. Ramkumar, B.; Oxidn Commun, 2001, 24 (4), 554-557.

46. Ramkumar, B.; Santhoshkumar, V.; Rukmangathan, M.; Int. J Chem Pharm Sci, 2014, 2(9), 1137-1141.

47. Ramkumar, B.; Rukmangathan, M.; Santhoshkumar, V.; Der Chemica Sinica, Pelagia Research Library, 2013, 4 (5), 106-111.

48. Kuselan, P.; Venkatasubramanian, N.; Indian J Chem, 1983, 22 (A), 292-297.

49. Mathur, A.; Banerji, K.K.; Indian J Chem, 1987, 26 (A), 774.

50. Suresh. C. Negi.; Kalyan K. Banerji.; Indian J Chem, 1982, 21 (B), 846-848.

51. Levitt, L.S.; Mallinowski, E.R.; J A Chem Soc, 1955, 77, 4517.

52. Vivekanandan, K.; Nambi, K.; J. Indian Chem Soc, 1999, 76, 198-201.

53. Srinivasan, N.S.; Venkatasubramanian, N.; Tetrahedron, 1974, 30, 419-425. 
(Tables \& Figures)

Table. 1

Effect of varying $[\mathrm{CBI}]$, [alcohol $],\left[\mathrm{HClO}_{4}\right],[\mathrm{NaCl}]$ and \% acetic acid

\begin{tabular}{|c|c|c|c|c|c|}
\hline \multicolumn{5}{|c|}{ Temperature } & \multirow{2}{*}{$\begin{array}{c}=308 \mathrm{~K} \\
\begin{array}{c}\mathbf{k}_{\text {obs }} \mathbf{s}^{-1} \\
\times \mathbf{1 0}^{\mathbf{4}}\end{array}\end{array}$} \\
\hline $\begin{array}{l}{[\mathrm{CBI}] \times 10^{3}} \\
\text { mol.dm }^{-3}\end{array}$ & $\begin{array}{c}{[\text { Alcohol }] \times 10^{2}} \\
\text { mol.dm }^{-3}\end{array}$ & $\begin{array}{l}{\left[\mathrm{H}^{+}\right] \times 10^{2}} \\
\text { mol.dm }\end{array}$ & $\begin{array}{l}{\left[\mathrm{Cl}^{-}\right] \times \mathbf{1 0}^{2}} \\
\text { mol.dm }\end{array}$ & $\begin{array}{c}\% \text { acetic } \\
\text { acid }\end{array}$ & \\
\hline 1.50 & 3.00 & 1.50 & 6.00 & 80 & 2.30 \\
\hline 2.25 & 3.00 & 1.50 & 6.00 & 80 & 2.27 \\
\hline 3.00 & 3.00 & 1.50 & 6.00 & 80 & 2.20 \\
\hline 3.75 & 3.00 & 1.50 & 6.00 & 80 & 2.16 \\
\hline 4.50 & 3.00 & 1.50 & 6.00 & 80 & 2.22 \\
\hline 3.00 & 1.50 & 1.50 & 6.00 & 80 & 1.16 \\
\hline 3.00 & 3.00 & 1.50 & 6.00 & 80 & 2.20 \\
\hline 3.00 & 4.50 & 1.50 & 6.00 & 80 & 3.36 \\
\hline 3.00 & 6.00 & 1.50 & 6.00 & 80 & 4.34 \\
\hline 3.00 & 7.50 & 1.50 & 6.00 & 80 & 5.76 \\
\hline 3.00 & 3.00 & 0.60 & 6.00 & 80 & 1.30 \\
\hline 3.00 & 3.00 & 1.50 & 6.00 & 80 & 2.20 \\
\hline 3.00 & 3.00 & 2.40 & 6.00 & 80 & 2.70 \\
\hline 3.00 & 3.00 & 3.60 & 6.00 & 80 & 3.68 \\
\hline 3.00 & 3.00 & 4.50 & 6.00 & 80 & 4.10 \\
\hline 3.00 & 3.00 & 1.50 & 3.60 & 80 & 1.48 \\
\hline 3.00 & 3.00 & 1.50 & 6.00 & 80 & 2.20 \\
\hline 3.00 & 3.00 & 1.50 & 9.60 & 80 & 3.35 \\
\hline 3.00 & 3.00 & 1.50 & 14.40 & 80 & 4.42 \\
\hline 3.00 & 3.00 & 1.50 & 18.00 & 80 & 5.19 \\
\hline 3.00 & 3.00 & 1.50 & 6.00 & 60 & 1.08 \\
\hline 3.00 & 3.00 & 1.50 & 6.00 & 70 & 1.45 \\
\hline 3.00 & 3.00 & 1.50 & 6.00 & 80 & 2.20 \\
\hline 3.00 & 3.00 & 1.50 & 6.00 & 90 & 5.40 \\
\hline
\end{tabular}


Table. 2

Effect of substituents
$[\mathrm{CBI}]=3.0 \times 10^{-3} \mathrm{~mol} . \mathrm{dm}^{-3}$ $\left[\mathrm{HClO}_{4}\right]=1.5 \times 10^{-2} \mathrm{~mol} \mathrm{dm}^{-3}$ [Alcohol $]=3.0 \times 10^{-2}$ mol. $\mathrm{dm}^{-3}$
$[\mathrm{NaCl}]=6.0 \times 10^{-2} \mathrm{~mol} \mathrm{dm}^{-3}$
Solvent $\quad=80 \% \mathrm{CH}_{3} \mathrm{COOH}$
Temperature $=308 \mathrm{~K}$

\begin{tabular}{|c|c|c|c|c|c|c|c|c|c|c|c|}
\hline Substituents & $\mathrm{H}$ & $\begin{array}{l}p- \\
\mathrm{OCH}_{3}\end{array}$ & $\begin{array}{c}p- \\
\mathrm{CH}_{3}\end{array}$ & $\begin{array}{c}p- \\
\mathrm{Br}\end{array}$ & $\begin{array}{c}p- \\
\mathrm{Cl}\end{array}$ & $\begin{array}{c}p- \\
\mathrm{NO}_{2}\end{array}$ & $\begin{array}{c}m- \\
\mathrm{OCH}_{3}\end{array}$ & $\begin{array}{c}m- \\
\mathrm{CH}_{3}\end{array}$ & $\begin{array}{c}m- \\
\mathrm{Br}\end{array}$ & $\begin{array}{c}m- \\
\mathrm{Cl}\end{array}$ & $\begin{array}{c}m- \\
\mathrm{NO}_{2}\end{array}$ \\
\hline $\mathbf{k}_{\text {obs }} \mathbf{s}^{-1} \times \mathbf{1 0}^{4}$ & 2.20 & 7.22 & 4.60 & 2.16 & 1.73 & 0.96 & 2.57 & 1.59 & 1.19 & 1.21 & 1.24 \\
\hline
\end{tabular}

Table. 3

Arrhenius parameters for the oxidation of Benzyl alcohol by CBI

\begin{tabular}{|c|c|c|c|c|c|c|c|c|c|c|c|c|}
\hline \multirow{2}{*}{ S.No } & \multirow{2}{*}{ Thermodynamic functions } & \multicolumn{11}{|c|}{ Substituents } \\
\hline & & $\mathbf{H}$ & $p-\mathrm{OCH}_{3}$ & $\mid p-\mathrm{CH}_{3}$ & $p-\mathrm{Br}$ & $p-\mathrm{Cl}$ & $p-\mathrm{NO}_{2}$ & ${ }_{2} \mathrm{~m}-\mathrm{OCH}_{3}$ & $m-\mathbf{C H}$ & ${ }_{3} m-\mathbf{B r}$ & $m-\mathbf{C l}$ & $\begin{array}{c}m- \\
\mathrm{NO}_{2}\end{array}$ \\
\hline 1 & $\mathrm{E}_{\mathrm{a}} \mathrm{KJ}$ mol-1 & 32.68 & 29.07 & 35.10 & 38.09 & 35.39 & 35.05 & 33.87 & 39.63 & 35.70 & 35.70 & 37.64 \\
\hline 2 & $\Delta \mathrm{H}^{\#} \mathrm{KJ}$ mol-1 & 30.12 & 26.51 & 32.54 & 35.53 & 32.83 & 32.49 & 31.31 & 37.07 & 33.14 & 33.14 & 35.08 \\
\hline 3 & $\Delta \mathrm{G}^{\#} \mathrm{KJ}$ mol-1 & 97.00 & 94.30 & 95.13 & 97.03 & 97.21 & 97.32 & 96.83 & 97.98 & 98.54 & 98.54 & 97.45 \\
\hline 4 & $-\Delta \mathrm{S}^{\#} \mathrm{KJ}$ mol-1 & 217.16 & 219.24 & 203.23 & 199.70 & 210.51 & 210.51 & 212.75 & 197.76 & 212.34 & 212.34 & 205.52 \\
\hline 5 & $\ln \mathrm{A}$ & 4.342 & 4.119 & 6.03 & 6.43 & 5.16 & 5.12 & 5.05 & 6.73 & 4.91 & 4.91 & 5.70 \\
\hline
\end{tabular}

Table. 4

Nature of Reaction series and selectivity

\begin{tabular}{|c|c|c|c|c|}
\hline S. No. & Characterization & \multicolumn{2}{|c|}{ Slope } & Selectivity \\
\hline 1 & $\log$ A Constant & $\mathrm{T}_{1} / \mathrm{T}_{2}$ & - & Decreases \\
\hline 2 & Ea Constant & 1 & 0 & Unchanged \\
\hline $3 \mathrm{a}$ & Compensation effect & $<\mathrm{T}_{1} / \mathrm{T}_{2}$ & $>\mathrm{T}_{2}$ & Decreases \\
\hline $3 b$ & Compensation effect & $>1$ & $<\mathrm{T}_{1}$ & Increases \\
\hline $3 c$ & Compensation effect & $<0$ & ${ }_{2}>\mathrm{T}_{1}$ & Increases \\
\hline
\end{tabular}


Table. 5

Hydrolytic and true formation constants of $\mathrm{NCSH}^{+}, \mathrm{CBTH}^{+}$and $\mathrm{CBIH}^{+}$

\begin{tabular}{|c|l|c|c|}
\hline S. NO & OXIDANT & $\mathbf{K}_{\mathbf{h}}$ & $\overline{\mathbf{K}}$ \\
\hline & & & \\
1 & NCS [53] & 0.46 & 78.4 \\
2 & CBT [48] & 0.78 & 694 \\
3 & CBI & 1.63 & 711 \\
& & & \\
\hline
\end{tabular}

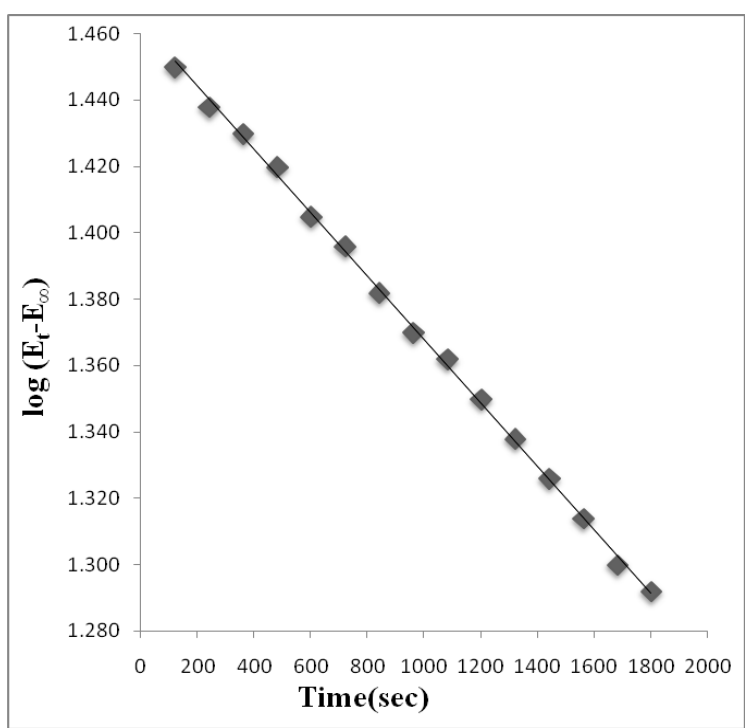

Fig. 1. First order plot of CBI

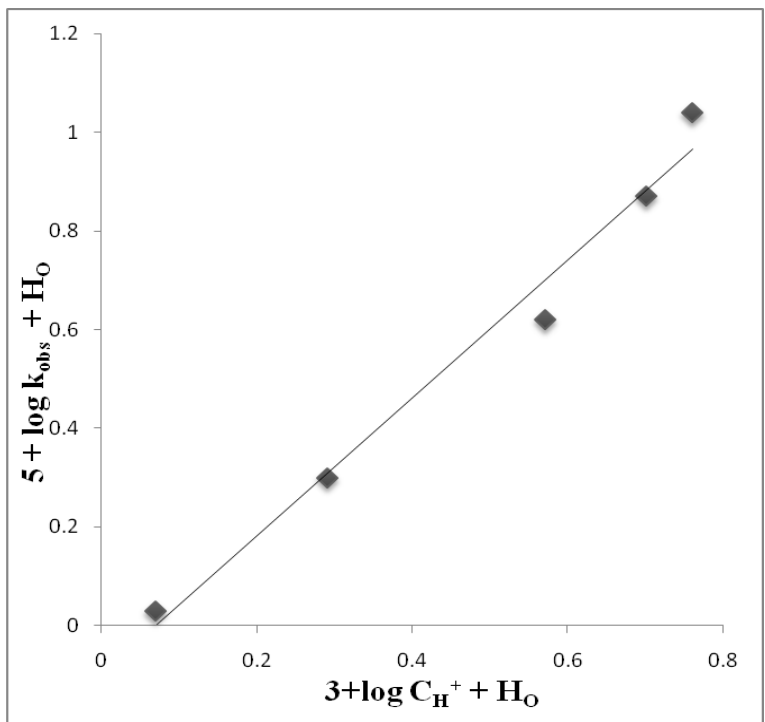

Fig .2. Bunnett - Olsen plot 


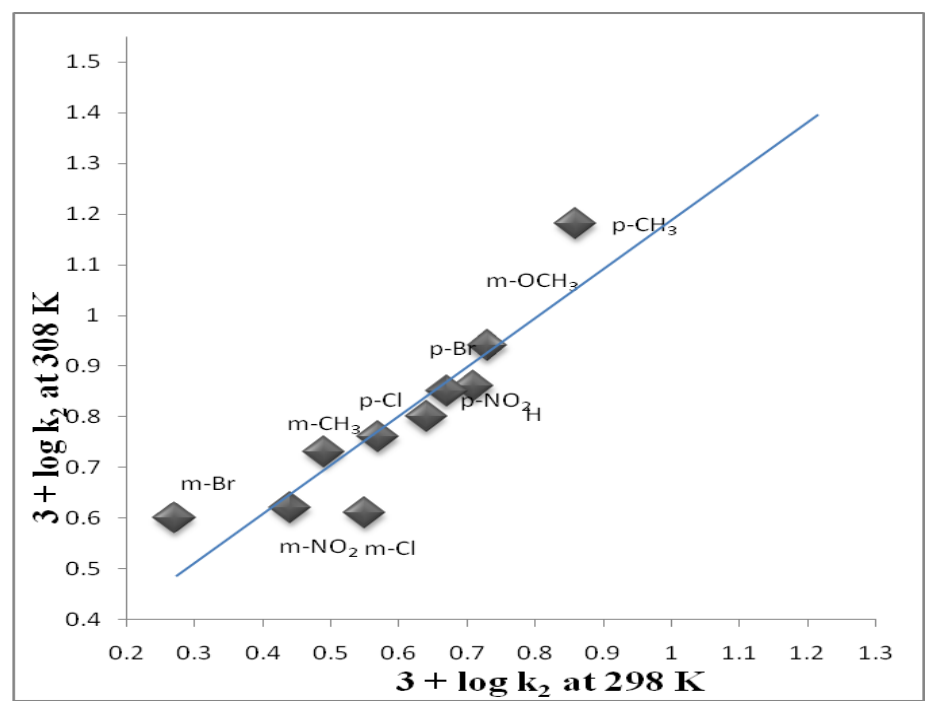

Fig.3. Exner Plot

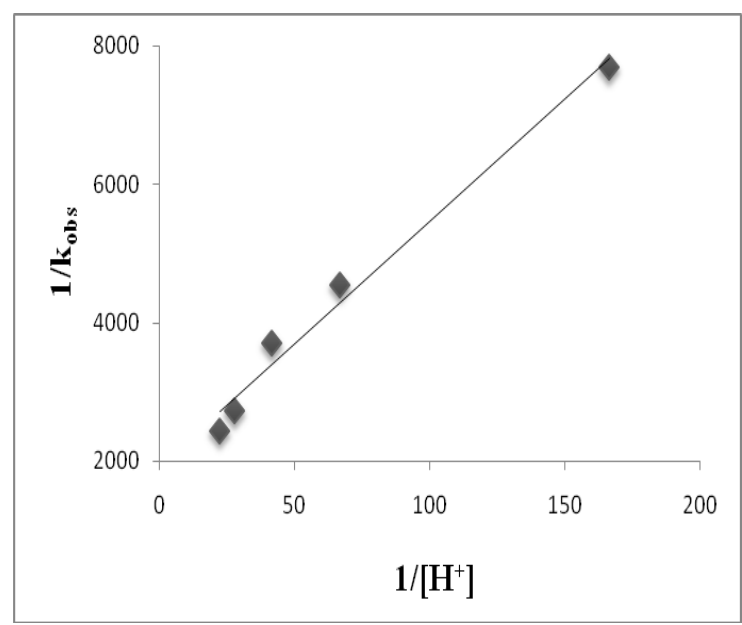

Fig.4. Plot of $1 / \mathrm{k}_{\mathrm{obs}} \mathrm{Vs} 1 /\left[\mathrm{H}^{+}\right]$

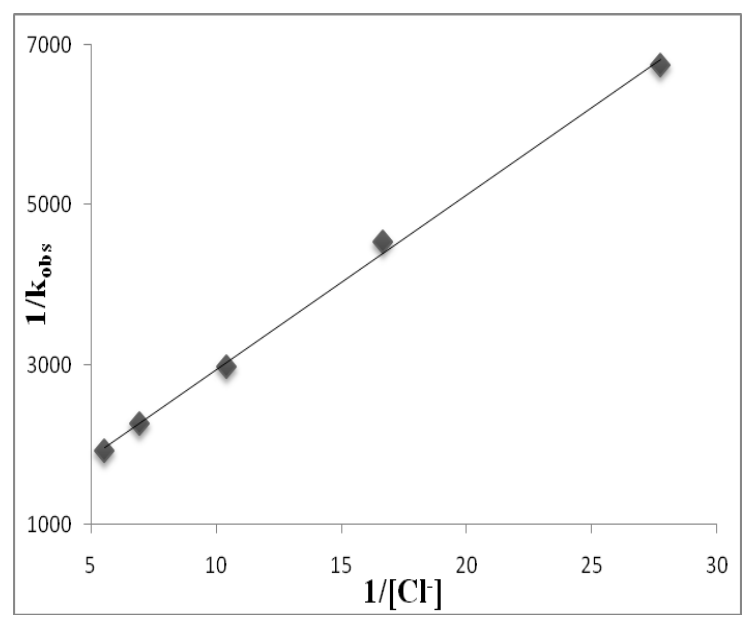

Fig.5. Plot of $1 / \mathrm{k}_{\text {obs }} \mathrm{Vs} \mathbf{1} /\left[\mathrm{Cl}^{-}\right]$ 


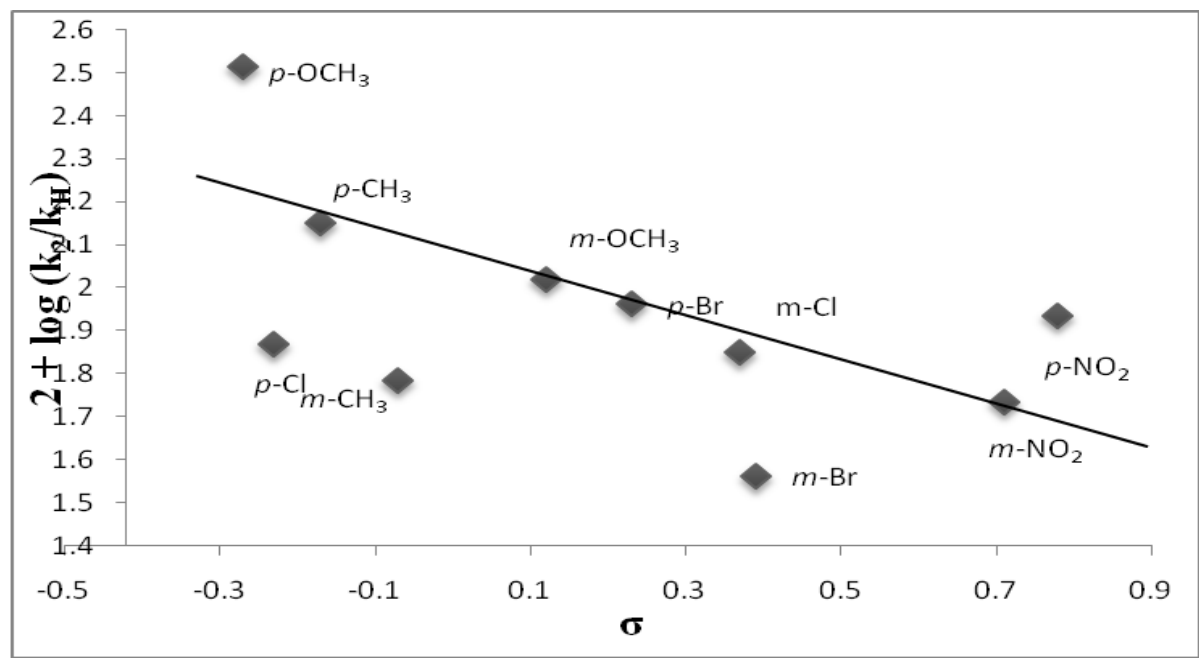

Fig.6. Plot of $\log \left(k_{2} / k_{H}\right)$ Vs $\sigma$ at $298 K$ 